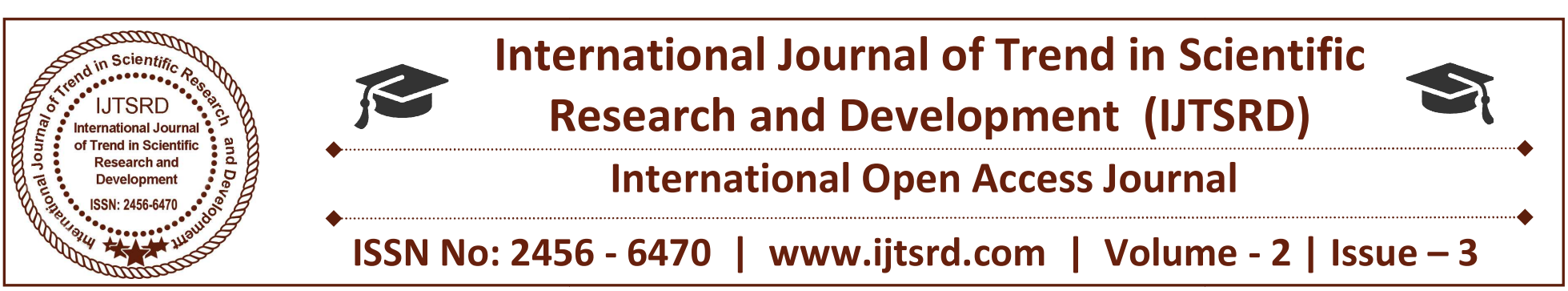

\title{
Review on Earth Observation and Space Museum Application
}

\author{
Anjum Shaikh, Pranita Tiwari, Prof. Itrat Fatema \\ Department of Computer Science and Engineering, \\ Anjuman College Of Engineering. \& Technology, Sadar, Nagpur, Maharashtra, India
}

\begin{abstract}
In recent years, Earth Observation has become technologically increasingly sophisticated. It has also become more important due to the dramatic impact that modern human civilization is having on the planet Earth, and the need to minimize negative impacts along with the opportunities. Earth observation provides to improve social and economic well-being. The Space Museum is the collection of space crafts, air craft's, satellites and other celestial bodies.
\end{abstract}

Keywords: Earth Observation and Space- Museum Application

\section{INTRODUCTION}

Our project is an application for mobile phones that supports android operating system. It uses the Augmented Reality Technology, that simulates object in real environment and Virtual Reality that creates virtual environment. The entire project is about representing geologic observations in effective manner and space museum in very interactive way. In this project we a have two module i.e. Earth observation and Space museum. In first module that is Earth Observation, it incorporate images, videos, AR models, and its details. As soon as the user access this application, four components i.e. images, video, AR models, and animated videos will appear on the screen. According to the interest of the individual user, they can access above components. On the basis of user's interest they can traverse through either of the buttons, which lead them to another page that contains four sub components. These sub four components allows user to acquire essential facts.

\section{PROJECT MODULE}

This project contains two main module i.e. Earth observation and Space museum.

In the first module we will create a user-interactive environment and this will help user to acquire knowledge about Earth in various forms as mention in its components. There are four components i.e. images, videos, AR model, animated videos. Images contain various types of images that are captured from satellite which shows the different information about earth. Videos contains VR videos of earth.AR model contains AR 3D model of earth. Animated videos contain animate description of earth. This will provide unique experience to individual user to understand and learn in a better manner. In the second module we will create a virtual space museum which contains all the information about space museum exhibits. This module also contains four components i.e. images, videos, AR model, animated videos but for space museum. Images contain various types of images that are captured from satellite which shows the different information about space. Videos contains VR videos of space museum .AR model contains AR 3D model of satellite. Animated videos contain animate description of space museum.

\section{IMPLIMENTATION}

The proposed system highlights on virtual space museum and earth observation which provides information in very interactive way. Virtual Space museum provides images, animated videos and VR videos of the space museums. Earth observation, provides images, animated videos and 3D model earth model. 


\subsection{Working of Application}

This is an educational type of application, which contain all type of information related to earth observation and space museum.

This application contains two modules that is Earth observation and space museum. As soon as user opens this application first page will appear which contain two buttons, first button is of Earth observation and second button is of Space museum.

\section{CONCLUSION}

It is concluded that the application works well and satisfy the end users. This system is user friendly so everyone can use easily. Proper documentation is provided.

The end user can easily understand how the whole system is implemented by going through the documentation. The system is tested, implemented and the performance is found to be satisfactory. All necessary output is generated.

Further enhancements can be made to the application, so that the application functions very attractive and useful manner than the present one.

\section{FUTURE SCOPE}

There is scope for future development of this project. The world of computer fields is not static; it is always subject to be dynamic. The technology which is famous today becomes outdated the very next day. To keep abstract of technical improvements, the system may be further referred. So, it is not concluded. Yet it will improve with further enhancements.

Enhancements can be done in an efficient manner. We can even update the same with further modification establishment and can be integrated with modification. Thus the project is flexible and can be updated at anytime with more advanced features.

\section{ACKNOWLEDGEMENT}

We would like to thank Prof. Itrat Fatema (Asst. Prof, CSE) Anjuman College of Engineering and Technology; because of their guidance we are able to do our project successfully during the entire course.

We would also like to thank to all those who have contributed, directly or indirectly to make this project successful.

\section{REFERENCES}

1. Simulation of Earth Observation from an Orbit. Published in: Journal of the SMPTE (Volume: 75 , Issue: $1^{\text {st } J a n u a r y ~} 1966$ )

2. file:///E:/B.E.\%20Project/Information/AR\%20VR/ $5 \% 20 \mathrm{Key} \% 2$

0Components $\% 20$ of $\% 20$ Virtual $\% 20$ Reality $\% 20$ S ystems $\% 20-\% 20$ AppReal.html

3. file:///E:/B.E.\%20Project/Information/AR\%20VR/ Explained_\%20How\%20does\%20VR\%20actually \%20work_html

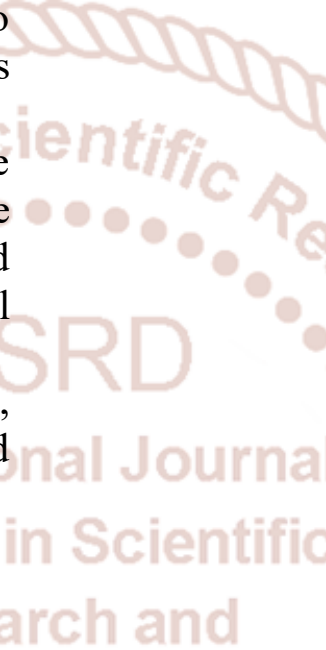

